\title{
Inhibition of Halobacterium cutirubrum Lipid Biosynthesis by Bacitracin
}

\author{
By G. WILLIAM BASINGER AND JAMES D. OLIVER \\ Department of Biology, University of North Carolina at Charlotte, \\ Charlotte, North Carolina 28223, U.S.A.
}

(Received 12 July 1978; revised 23 October 1978)

\begin{abstract}
Halobacterium cutirubrum, an extremely halophilic bacterium, lacks a normal peptidoglycan cell wall. Nevertheless, bacitracin, a known inhibitor of peptidoglycan synthesis, has been shown to completely suppress the growth of this organism (Mescher \& Strominger, 1975). In an attempt to clarify this observation, the effect of bacitracin on DNA, RNA, protein and lipid biosynthesis in $H$. cutirubrum was monitored. Lipid carbohydrate and lipid phosphate were the most affected. These observations were confirmed by uptake studies of $\left[{ }^{14} \mathrm{C}\right]$ glycerol into the membrane lipids. The possibility that bacitracin acts against H. cutirubrum through inhibition of dephosphorylation of the isoprenoid pyrophosphate precursors of this organism's diether lipids is discussed.
\end{abstract}

\section{INTRODUCTION}

Mescher \& Strominger (1975) assayed the sensitivity of various species of Halobacterium to a wide variety of agents inhibiting peptidoglycan synthesis. The only antibiotic found to have significant effect on the growth of halobacteria was bacitracin, although peptidoglycan has not been shown to occur in cell envelopes of the halobacteria (Kushner et al., 1964). The authors suggested that the effect of bacitracin may be due to the inhibition of synthesis of a large molecular weight glycoprotein found in the cell envelope of a Halobacterium species (Mescher et al., 1974). This glycoprotein accounts for $50 \%$ of the total envelope protein and may function in a manner similar to peptidoglycan in providing structural integrity to the cell envelope (Mescher \& Strominger, 1976). Mescher \& Strominger (1975) also suggested that the effect of bacitracin on the growth of halobacteria may be due to some effect on the membrane lipids. The polar membrane lipids of halobacteria, consisting of approximately $60 \%$ phospholipid and $35 \%$ glycolipid (Kates, 1972), are completely different from those of non-halophilic and moderately halophilic bacteria (Kates et al., 1965). Whereas the side-chains occurring in other bacterial polar lipids are fatty acids in ester linkage to the glycerol moiety, those of the extreme halophiles are composed exclusively of phytanyl (20 carbon isoprenoid) groups attached to glycerol through an ether linkage (Kates et al., 1965). Although bacitracin has not been reported to affect lipid synthesis, such an effect seemed possible due to the structural similarity between the isoprenoid pyrophosphate precursors active in normal peptidoglycan synthesis (Siewert \& Strominger, 1967) and those proposed to be involved in the synthesis of the polar lipids present in the extreme halophiles (Kates et al., 1970).

In addition to bacitracin's known ability to inhibit peptidoglycan synthesis, this antibiotic has been shown to possess surfactant properties (Smith \& Weinberg, 1962) and to inhibit bacterial protein synthesis (Park, 1961). Thus, since numerous potential sites of bacitracin action in halobacteria were possible, we have studied the effects of the antibiotic on a wide variety of cell constituents (DNA, RNA, protein, lipid carbohydrate and lipid phosphate). 


\section{METHODS}

Media and growth conditions. Halobacterium cutirubrum was grown in a standard halophile medium (Sehgal \& Gibbons, 1960) at $39{ }^{\circ} \mathrm{C}$ with vigorous shaking. Cell growth was monitored by absorption at $660 \mathrm{~nm}$. Bacitracin ( $15 \mu \mathrm{g} \mathrm{ml}^{-1}$ final concentration; Sigma) was added to the test culture in mid-exponential growth, and samples were removed at various intervals for chemical assay. Control cultures received an equal volume $(1 \mathrm{ml})$ of distilled water in place of bacitracin, and were otherwise treated in the same manner as the test cultures. Conversion to spherical forms after addition of bacitracin was monitored by phase contrast microscopy.

Analytical techniques. After extraction and separation of RNA and DNA by the method of Halliburton \& Thomson (1965), DNA was quantified as described by Ceriotti (1952) and RNA was determined by its absorbance at $260 \mathrm{~nm}$. Protein was assayed by the method of Lowry et al. (1951). Total lipids were extracted according to Bligh \& Dyer (1959); the amount of lipid carbohydrate was determined by the phenol-sulphuric acid method of Dubois et al. (1956) and lipid phosphate by that of Ames \& Dubin (1960).

Radioactive labelling of bacterial lipids. Samples $(2 \mathrm{ml})$ of control and bacitracin-treated cultures were removed at various intervals and pulse-labelled with $1 \mu \mathrm{Ci}$ of $\left[\mathrm{U}^{-14} \mathrm{C}\right] \mathrm{glycerol}\left(20 \mathrm{mCi} \mathrm{mmol}{ }^{-1}\right.$; ICN) for 10 min with shaking at $39^{\circ} \mathrm{C}$. Labelling was stopped by adding methanol and the lipids were immediately extracted into chloroform as described by Bligh \& Dyer (1959). Incorporation was monitored by liquid scintillation counting of a sample of the ${ }^{14} \mathrm{C}$-labelled lipids.

Statistical treatment of results. ' $F$ ' tests were performed on the linear regression lines calculated for all analytical results for samples collected at times during cell growth when equal cell numbers (indicated by absorption at $660 \mathrm{~nm}$ ) were present in control and bacitracin-treated cultures.

\section{RESULTS}

Effect of bacitracin on morphology and growth. The addition of bacitracin to exponential phase cultures of $H$. cutirubrum resulted in a slow conversion of the normal rod-shaped cells to spherical forms. The latter were first seen $4 \mathrm{~h}$ after addition of the antibiotic, and complete conversion occurred within $22.5 \mathrm{~h}$. These observations confirm those of Mescher \& Strominger (1975), although they used bacitracin at $30 \mu \mathrm{g} \mathrm{ml}^{-1}$.

Growth of control and bacitracin-treated cultures remained parallel for $5 \mathrm{~h}$ (approximately one cell generation) after addition of bacitracin, but then the rate of growth of the treated culture began to decrease. This time correlates well with the time at which individual cells were observed by phase contrast microscopy to begin rounding up.

Alteration of cell constituents on addition of bacitracin. Very little difference in DNA or RNA accumulation was observed between control and bacitracin-treated cultures (Fig. 1). The small differences indicated between the curves were not statistically significant $(P<$ $0 \cdot 01$ ) for either component when subjected to the ' $F$ ' test. Similarly, the linear regression lines calculated for the total protein values showed a very high degree of correlation (Fig. 2), and there was no statistical difference $(P<0.01)$ between the two curves.

In contrast to the results for DNA, RNA and protein accumulation in bacitracin-treated and control cultures, linear regression lines calculated for the results for lipid carbohydrate synthesis indicated a decrease $(P<0.01)$ of this component soon after addition of antibiotic to the test culture (Fig. $3 a$ ). The linear regression lines for lipid phosphate accumulation in control and bacitracin-treated cultures were also significantly different $(P<0.01)$, with divergence of the two curves occurring immediately after the antibiotic was added to the test culture (Fig. $3 b$ ).

Effect of bacitracin on uptake of $\left[{ }^{14} \mathrm{C}\right]$ glycerol into cellular lipids. Figure 4 presents the results of the pulse-labelling study of the lipids of $H$. cutirubrum. The radiolabel employed, $\left[{ }^{14} \mathrm{C}\right]$ glycerol, has been shown by Kates et al. (1970) to be incorporated into the lipids. The control culture exhibited a linear increase in total incorporation of $\left[{ }^{14} \mathrm{C}\right]$ glycerol into the lipids, as expected for an increasing number of cells. The bacitracin-treated culture, however, showed an immediate decrease in ability to incorporate label into the lipid fraction, although the number of cells continued to increase in the same manner as in the 

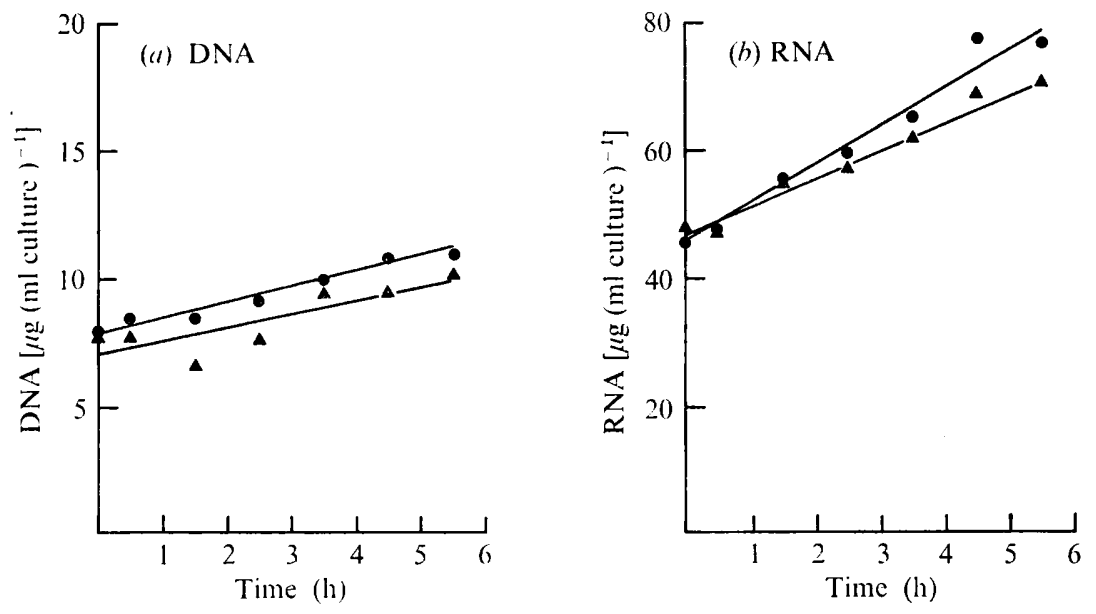

Fig. 1. Effect of bacitracin on the accumulation of DNA $(a)$ and RNA $(b)$ in $H$. cutirubrum. Linear regression lines were calculated for the individual nucleic acids extracted from samples of bacitracintreated $(\boldsymbol{A})$ and control $(\boldsymbol{O})$ cultures during the period of growth when the two cultures contained equal numbers of cells.

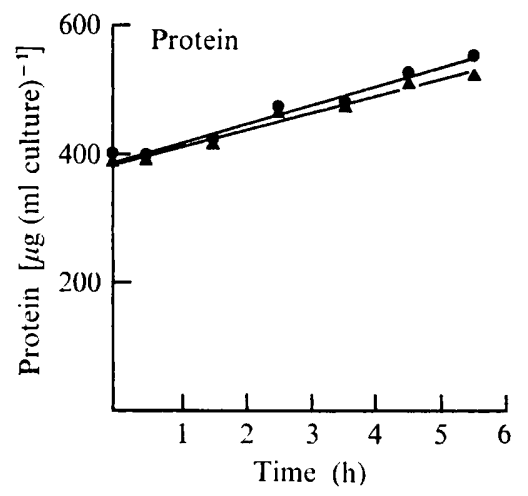

Fig. 2. Effect of bacitracin on protein accumulation in $H$. cutirubrum: $\mathbf{\Delta}$, bacitracin-treated culture; , control. For details, see Fig. 1.
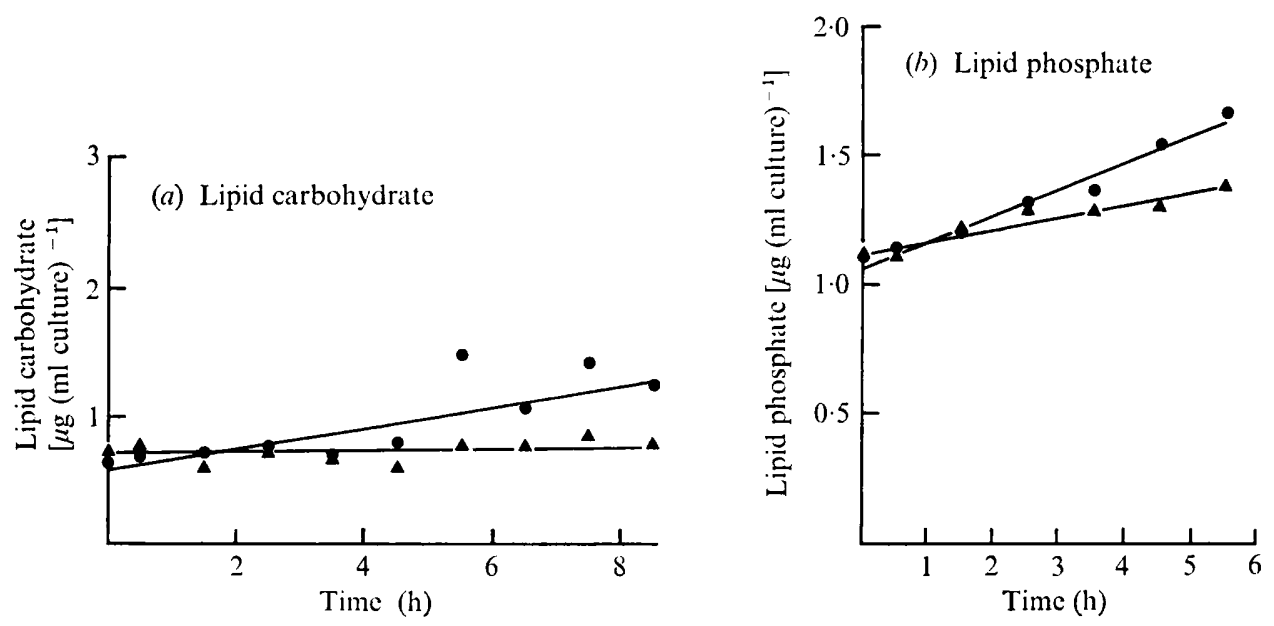

Fig. 3. Effect of bacitracin on the accumulation of lipid carbohydrate (a) and lipid phosphate $(b)$ in $H$. cutirubrum: $\mathbf{\Delta}$, bacitracin-treated culture;

, control. For details see Fig. 1. 


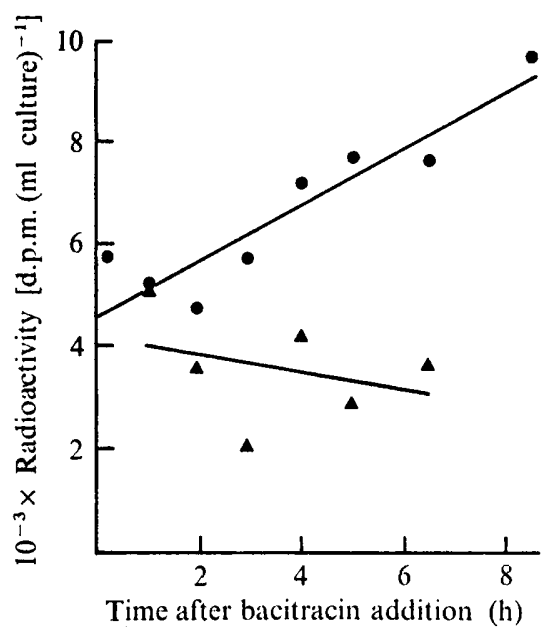

Fig. 4. Effect of bacitracin on the uptake of $\left[{ }^{14} \mathrm{C}\right]$ glycerol into cellular lipids. Cells in $2 \mathrm{ml}$ samples of culture taken at the times indicated were pulse-labelled for $10 \mathrm{~min}$ with $\left[\mathrm{U}-{ }^{14} \mathrm{C}\right] \mathrm{glycerol}$; the lipids were then extracted and analysed for ${ }^{14} \mathrm{C}$ incorporation. Linear regression lines were calculated for bacitracin-treated $(\boldsymbol{\Delta})$ and control $(\mathbf{O})$ cells.

control for approximately one generation. An ' $F$ ' test on the linear regression lines calculated from the results indicated that the two curves were statistically different $(P<0.01)$, further supporting the above observations on lipid phosphate and carbohydrate.

\section{DISCUSSION}

The significant changes observed in lipid carbohydrate and lipid phosphate accumulation after the addition of bacitracin indicate that the antibiotic exerts its primary effect on the synthesis of the glycolipids and phospholipids of Halobacterium cutirubrum. These conclusions are supported by the overall decrease in lipid synthesis indicated in the $\left[{ }^{14} \mathrm{C}\right]-$ glycerol uptake studies. The essentially identical total protein curves obtained for control and bacitracin-treated cultures indicate that the antibiotic had very little, if any, effect on protein synthesis in $H$. cutirubrum. The protein curves also support the assumption that equal numbers of metabolizing cells were present in both cultures during the sampling period. The possibility proposed by Mescher \& Strominger (1975) that the activity of bacitracin against halobacteria is due to inhibition of synthesis of the large molecular weight glycoprotein present in the cell envelope does not seem likely. Since this component accounts for over $50 \%$ of the total envelope protein, such an effect should be reflected in significantly decreased protein levels.

Horne et al. (1977) recently provided evidence that cellular lipids are released from a number of Gram-positive species into the surrounding medium on treatment with certain antibiotics which inhibit wall synthesis. The apparent decrease in lipid synthesis on addition of bacitracin that we observed was based on procedures involving sedimentation of the bacteria prior to extraction of the various cellular constituents and so could reflect lipids released in such a manner. The method of lipid extraction used during the radioactivity studies, however, involved extraction of both cells and spent growth medium; this study also indicated decreased lipid synthesis. Taken together, these two methods of assay suggest that, when bacitracin is added to $H$. cutirubrum, cellular lipids are not lost to the medium, but that lipid synthesis is inhibited. Thus, the surfactant properties of bacitracin do not seem to be important in its activity against $H$. cutirubrum.

Kates et al. (1970) proposed a pathway for the synthesis of the diether phosphoand glycolipids occurring in halobacteria. In this pathway, the immediate precursor of the 
phytanyl side-chains is a phytanyl pyrophosphate which must be dephosphorylated prior to attachment to the glycerol moiety. Bacitracin has been shown to bind to and inhibit the dephosphorylation of isoprenoid pyrophosphate structures with a wide variety of chain lengths, including those involved in peptidoglycan synthesis (Storm \& Strominger, 1973). The 20 carbon isoprenoid (phytanyl) pyrophosphate could similarly be bound by bacitracin. Since all of the polar membrane lipids in halobacteria possess exclusively these phytanyl side-chains, it seems reasonable to suppose that if the dephosphorylation of the side-chain precursor was inhibited, the synthesis of the total polar lipid complement would be drastically affected. Our observations on the effect of bacitracin on $H$. cutirubrum lipid biosynthesis are consistent with such a pathway.

Further quantitative and electrophoretic studies should clarify whether bacitracin has any effect on the large molecular weight cell envelope glycoprotein. Whether bacitracin's effect on the polar lipids of $H$. cutirubrum is generalized, or whether certain target lipids exist, also awaits further investigation.

This study was supported in part by a grant to J.D.O. from the Foundation of the University of North Carolina at Charlotte. This paper is submitted in partial fulfilment of the requirements of the M.S. degree at UNCC by G.W.B.

\section{REFERENCES}

AMEs, B. N. \& DuBIN, D. T. (1960). The role of polyamines in the neutralization of bacteriophage deoxyribonucleic acids. Journal of Biological Chemistry 235, 769-775.

Bligh, E. G. \& DYER, W. J. (1959). A rapid method of total lipid extraction and purification. Canadian Journal of Biochemistry and Physiology 37, 911917.

Ceriotti, G. (1952). A micro-chemical determination of deoxyribonucleic acid. Journal of Biological Chemistry 198, 297-303.

Dưbois, M., Gilles, K. A., Hamilton, J. K., Rebers, P. A. \& SMith, F. (1956). Colorimetric method for determination of sugars and related substances. Analytical Chemistry 28, 350-356.

Halliburton, I. W. \& Thomson, R. Y. (1965). Chemical aspects of compensatory renal hypertrophy. Cancer Research 25, 1882.

Horne, D., Hakenbeck, R. \& Tomasz, A. (1977). Secretion of lipids induced by inhibition of peptidoglycan synthesis in streptococci. Journal o, Bacteriology 132, 704-717.

KATES, M. (1972). Ether-linked lipids in extremely halophilic bacteria. In Ether Lipids, Chemistry and Biology, pp. 351-398. Edited by F. Snyder. New York: Academic Press.

Kates, M., Yengoyan, L. S. \& Sastry, P. S. (1965). A diether analog of phosphatidylglycerophosphate in Halobacterium cutirubrum. Biochimica et biophysica acta 98, 252-268.

Kates, M., Wassef, M. I. \& Pugh, E. L. (1970). Origin of the glycerol moieties in the glycerol diether lipids of Halobacterium cutirubrum. Biochimica et biophysica acta 202, 206-208.

Kushner, D. J., BAyley, S. T., Boring, J., Kates, M. \& Gibbons, N. E. (1964). Morphological and chemical properties of cell envelopes of the extreme halophile, Halobacterium cutirubrum. Canadian Journal of Microbiology 10, 483497.
Lowry, O. H., Rosebrough, N. J., Farr, A. L. \& RANDALL, R. J. (1951). Protein measurement with the Folin phenol reagent. Journal of Biological Chemistry 193, 265-275.

Mescher, M. F. \& Strominger, J. L. (1975). Bacitracin induces sphere formation in Halobacterium species which lack a wall peptidoglycan. Journal of General Microbiology 89, 375-378.

Mescher, M. F. \& Strominger, J. L. (1976). Purification and characterization of a prokaryotic glycoprotein from the cell envelope of Halobacterium salinarium. Journal of Biological Chemistry 251, 2005-2014.

Mescher, M. F., Strominger, J. L. \& Watson, S. W. (1974). Protein and carbohydrate composition of the cell envelope of Halobacterium salinarium. Journal of Bacteriology 120, 945-954.

PARK, J. T. (1961). Inhibition of synthesis of bacterial mucopeptide or protein by certain antibiotics and its possible significance for microbiology and medicine. Antimicrobial Agents Annual, 338.

Sehgal, S. N. \& Gibbons, N. E. (1960). Effect of some metal ions on the growth of Halobacterium cutirubrum. Canadian Journal of Microbiology 6, 156-169.

Siewert, G. \& Strominger, J. L. (1967). Bacitracin, an inhibitor of the dephosphorylation of lipid pyrophosphate, an intermediate in the biosynthesis of bacterial cell walls. Proceedings of the National Academy of Sciences of the United States of America 57, 767-773.

Smith, J. L. \& Weinberg, E. D. (1962). Mechanisms of antibacterial action of bacitracin. Journal of General Microbiology 28, 559-569.

Storm, B. R. \& Strominger, J. L. (1973). Complex formation between bacitracin peptides and isoprenyl pyrophosphates. Journal of Biological Chemistry 248, 3940-3945. 